\title{
Correction to: Gossip as an Intrasexual Competition Strategy: Sex Differences in Gossip Frequency, Content, and Attitudes
}

\author{
Adam C. Davis $^{1}$ - Caroline Dufort ${ }^{2} \cdot$ Jessica Desrochers ${ }^{2}$ - Tracy Vaillancourt ${ }^{1}$. \\ Steven Arnocky ${ }^{2}$
}

Published online: 30 October 2017

(C) Springer International Publishing AG 2017

\section{Correction to: Evolutionary Psychological Science}

https://doi.org/10.1007/s40806-017-0121-9

In Table 1 of the published article, the mean and standard deviation values for women and men on the Tendency to Gossip Questionnaire (TGQ) are in the incorrect columns. Women had a $M=67.09(S D=19.47)$, whereas men had a $M=60.20(S D=17.91)$ on the TGQ.

The online version of the original article can be found at https://doi.org/ 10.1007/s40806-017-0121-9

\footnotetext{
Adam C. Davis

adavi154@uottawa.ca

1 Faculty of Education, University of Ottawa, 145 Jean-Jacques-Lussier, Ottawa, ON K1N6N5, Canada

2 Department of Psychology, Nipissing University, 100 College Drive, North Bay, ON P1B8L7, Canada
} 